ECOLOGICA, Vol. 28, No 102 (2021), 223-228

https://doi.org/ 10.18485/ecologica.2021.28.102.12

Originalni naučni rad

UDC: 001.818:502.131.1](497.11)

\title{
Izveštavanje o zaštiti životne sredine u funkciji održivog razvoja
}

\section{Reporting on environmental protection in the function of sustainable development}

\author{
Ivana Bešlić Rupić1*, Dragana Bešlić Obradović ${ }^{2}$, Bojan Rupić ${ }^{3}$ \\ 1,2ALFA BK Univerzitet, Palmira Toljatija 3, 11070 Beograd, Srbija, \\ ALFA BK University, 3 Palmira Toljatija, 11070 Belgrade, Serbia \\ ${ }^{3}$ Kapital revizija doo, Vojvode Mišića 1, 21000 Novi Sad, Srbija, \\ Kapital revizija doo, 1 Vojvode Mišića, 21000 Novi Sad, Serbia \\ *Autor za prepisku / Corresponding author \\ Rad primljen / Received: 14.05.2020, Rad prihvaćen / Accepted: 14.05.2021.
}

Sažetak: Poslovanje čiji je jedini cilj sticanje profita bez brige o društvu, okolini i stejkholderima, ne može biti dugoročno održivo. Iz tog razloga sve veći broj kompanija u svoje poslovne strategije inkorporira koncept korporativne društvene odgovornosti. Među njima zapaženo mesto pripada NIS grupi.

Tradicionalni sistem finansijskog izveštavanja, koji se pretežno zasniva na kvantitativnim informacijama, nije u mogućnosti da na adekvatan način odgovori na informacione zahteve stejkholdera kada su u pitanju informacije o društveno odgovornom i održivom poslovanju kompanija. Rastuća svest o potrebi očuvanja životne sredine i rešavanju socijalnih pitanja stvara pritisak na kompanije da povećaju svoju odgovornost prema okruženju i unaprede kvalitet izveštavanja o održivom razvoju. Svrha ovog rada je da istraži vezu između izveštavanja o zaštiti životne sredine i održivog razvoja.

Ključne reči: korporativna društvena odgovornost, nefinansijsko izveštavanje, ekološke i socijalne performanse, održivi razvoj.

\begin{abstract}
A business whose sole goal is to make a profit without caring about society, the environment, and stakeholders can not be sustainable in the long run. For this reason, an increasing number of companies are incorporating the concept of corporate social responsibility into their business strategies. Among them, the notable place belongs to the NIS group.

The traditional financial reporting system, which is mainly based on quantitative information, is not able to adequately respond to the information requirements of stakeholders when it comes to information on socially responsible and sustainable business operations of companies. Growing awareness of the need to preserve the environment and address social issues is putting pressure on companies to increase their responsibility to the environment and improve the quality of sustainable development.
\end{abstract}

Keywords: corporate social responsibility, non-financial reporting, environmental and social performance, sustainable development.

\footnotetext{
${ }^{1}$ orcid.org/0000-0001-8399-3252, e-mail: ivana.beslic.rupic@alfa.edu.rs

${ }^{2}$ orcid.org/0000-0003-2278-7046, e-mail: dragana.beslic.obradovic@alfa.edu.rs

${ }^{3}$ orcid.org/0000-0001-8789-4200, e-mail: bojan.rupic@gmail.com
} 


\section{UVOD / INTRODUCTION}

Izveštavanje o održivom razvoju / integrisano izveštavanje je za poslovne subjekte u Srbiji relativno nova praksa, koja se još uvek nalazi u fazama razvoja, a razlog tome su nedostatak obavezujuće regulative i nedavni razvoj globalnih smernica za integrisano izveštavanje, koje su objavljene krajem 2013. godine od strane Međunarodnog saveta za integrisano izveštavanje (International Integrated Reporting Council - IIRC). Od 1. jula 2018. godine, smernice su podeljene u 3 seta opštih standarda sa principima i zahtevima koji čine osnovu svakog izveštaja, kao i 3 ključne teme - ekonomija odnosno ekonomske performanse, zaštita životne sredine i društvo. Produkovani izveštaji mogu da budu sastavljeni na dobrovoljnoj osnovi ili kao posledica obavezujuće regulative, odnosno da budu objavljeni kao zasebni izveštaji ili kao sastavni deo godišnjeg obračuna privrednog društva. Od ovog koncepta izveštavanja se očekuje da posluži kao alat za poboljšanje komunikacije sa nefinansijskim stejkholderima $\mathrm{i}$ integrisanje tradicionalnih finansijskih mera performansi sa merama perfomansi na polju zaštite životne sredine i unapređenja uslova u socijalnom okruženju. Ovako sveobuhvatan sistem izveštavanja se oslanja na postojeće standarde međunarodnog finansijskog izveštavanja (MRS/MSFI) i postojeće smernice za izveštavanje o održivom razvoju.

Uvođenjem Zakona o računovodstvu iz 2013. godine ("SI. glasnik RS", br. 62/2013), pružena je polazna osnovu za izveštavanje o održivom razvoju, obavezujući velika i listirana privredna društva u Srbiji da počev od 2014. godine, kroz izveštaj o poslovanju, objavljuju širi spektar informacija o pojedinim aspektima održivosti poslovanja. MRS/MSFI pružaju značajnu polaznu osnovu za kreiranje kvalitetnih informacija o održivosti poslovanja, jer se pitanjima računovodstva zaštite životne sredine bave na primer, MRS 8, MRS 10, MRS 16, MRS 20, MRS 36, MRS 37, MRS 38, MRS 41, kao i MSFI 3, MSFI 6 i MSFI 8, itd. Sa druge strane, kritičari se pozivaju na ograničenja MRS/MSFI da ponude šire mogućnosti za priznavanje i vrednovanje troškova, obaveza i rizika vezanih za zaštitu životne sredine (Sekerez, 2016).

Naftna Industrija Srbije (NIS) a.d. Novi Sad, je prva među velikim kompanija u Srbiji koja je otpočela publikovanje zasebnog izveštaja o održivom razvoju, koji je verifikovan od strane nezavisnog revizora i u potpunosti usklađen sa globalno prihvaćenim Smernicama za globalno izveštavanje promovisanim od strane Globalne inicijative za izveštavanje (Global reporting initiative - GRI).

\section{MATERIJALI I METODE / MATERIALS AND METHODS}

Cilj ovog rada se sastoji u istraživanju uticaja koncepta održivog razvoja na razvoj prakse izveštavanja o održivom poslovanju i unapređenju životne sredine. Tom prilikom koristiće se kvalitativne metode, zasnovane na opservaciji i interpretiranju sadržaja postojećih istraživanja u literaturi, što će biti podržano studijom slučaja, tj. analizom tekuće prakse izveštavanja o zaštiti životne sredine na primeru domicilne kompanije NIS a.d.

\section{REZULTATI I DISKUSIJA / RESULTS AND DISCUSSION}

\subsection{Orijentisanost kompanija ka zaštiti životne sredine i nefinansijskom izveštavanju / Orientation of companies towards environmental protection and non-financial reporting}

$\mathrm{U}$ dvadeset prvom veku jedno od izazovnih pitanja je zaštita životne sredine. Iz tog razloga mnoge kompanije iz industrijskih zemalja širom sveta praktikuju merenje ekoloških performansi. Danas, sve veći broj domicilnih kompanija shvata ulogu računovodstva zaštite životne sredine u sticanju konkurentskih prednosti, a njegovo uključivanje u poslovanje predstavlja poseban izazov za menadžment. Orijentisanost kompanije ka zaštiti životne sredine važno je merilo uspešnosti poslovanja iz sledećih ključnih razloga (Baldarelli et al, 2017; Damnjanović i dr, 2020):

1. Postoje mogućnosti za potencijalno smanjenje troškova u vezi zaštite životne sredine, kao rezultat poslovnih rešenja za ekološku proizvodnju na temelju ulaganja u "zelenu" tehnologiju u proizvodni proces, i prilagođavanje ili modifikacija procesa i/ili proizvoda. Na primer, ušteda se može ostvariti zamenom otrovnih materijala koji se koriste $u$ proizvodnji s netoksičnim supstituentima, čime se eliminišu visoki i rastući troškovi obrade opasnog otpada i troškovi povezani s upotrebom toksičnog materijala.

2. Postoje mogućnosti za rast prihoda kompanije, na primer putem prodaje otpadnih nusproizvoda.

3. Uspostavljanje funkcionisanja sveobuhvatnog sistema za upravljanje zaštitom životne sredine, kao što je ISO 14001.

4. Kroz ekološko računovodstvo i izveštavanje o zaštiti životne sredine može se postići konkurentska prednost.

Sve više poslovnih subjekata u Srbiji usvaja koncept ekološkog menadžmenta i integriše principe održivog poslovanja, pa tako ostvaruju profit uz odgovorno ponašanje prema društvu $i$ životnoj 
sredini. Prelaskom na zelenu ekonomiju postiže se dalekosežna korist u vidu smanjenja negativnog uticaja kompanije na životnu sredinu. Zelena ekonomija je od izuzetnog značaja i za građane, jer radi na smanjenju siromaštva, razvoju ruralnih područja, a pritom vodi brigu o bezbednosti hrane, omogućavanju pristupa čistoj vodi i energiji kao i čitavom nizu pitanja zaštite životne sredine i biodiverziteta. Ključni koncepti ekološkog menadžmenta su: održivi razvoj, eko-efikasnost i čistija proizvodnja. Poslovnim subjektima su potrebni alati za merenje performansi koji moraju uključivati kvantitativne i kvalitativne varijable. Pored toga, treba definisati dimenzije, koje mogu pokazati korporativni održivi razvoj. Ove dimenzije su izvedene iz koncepta slabe i jake održivosti, eko-efikasnosti i eko-pravde, a prikazane su u Tabeli 1.

Tabela 1 - Dimenzije održivosti i alati za merenje

Table 1 - Sustainability dimensions and measurement tools

\begin{tabular}{|l|c|c|}
\hline \multirow{2}{*}{$\begin{array}{l}\text { Merenje održivosti i } \\
\text { komunikacioni alati }\end{array}$} & \multicolumn{2}{|c|}{ Tip održivosti } \\
\cline { 2 - 3 } $\begin{array}{l}\text { Eko-efikasnost } \\
\text { (odnos između promene u } \\
\text { vrednosti i promene u dodatnim } \\
\text { ekološkim uticajima) }\end{array}$ & $\begin{array}{c}\text { Ekološki upravljački sistem } \\
\text { (Eco Management Audit } \\
\text { Scheme -EMAS); Ekološki znak } \\
\text { Slabo izveštavanje o životnoj } \\
\text { sredini }\end{array}$ & $\begin{array}{c}\text { Proračun održivih troškova; } \\
\text { Računovodstvo punih troškova; } \\
\text { Računovodstvo životne sredine } \\
\text { i izveštavanje o održivosti }\end{array}$ \\
\hline Eko-pravda & & $\begin{array}{c}\text { Alati za odgovornost, eksterna } \\
\text { revizija }\end{array}$ \\
\hline
\end{tabular}

Izvor / Source: (Bebbinghton, 2007).

Prema programu Ujedinjenih nacija za životnu sredinu (United Nations Environmnet Programme UNEP) čistija proizvodnja predstavlja primenu sveobuhvatne preventivne strategije zaštite životne sredine na proizvodne procese, proizvode i usluge, sa ciljem povećanja ukupne efikasnosti i smanjenja rizika po zdravlje ljudi i životnu sredinu (United Nations Environment Programme (UNEP), The Global Reporting Initiative (GRI), KPMG \& The Centre for Corporate Governance in Africa, 2013). Investitori su zainteresovani za kvalitetne informacije o efektima aktivnosti kompanije na planu prevencije, ublažavanja ili otklanjanja negativnih uticaja na životnu sredinu, kako bi zaštitili svoja ulaganja od budućih gubitaka koji mogu nastati kao posledica tekućih rizika održivog razvoja (Thistlethwaite, 2011). Ranije je veoma mali broj kompanija u potpunosti obelodanjivao i kvantifikovao pomenute rizike u svojim godišnjim izveštajima namenjenim široj javnosti. Međutim, danas sve veći broj kompanija širom sveta obelodanjuje informacije u vezi društveno odgovornog poslovanja ili izveštaje o održivom razvoju kao dopuna godišnjem izveštaju (Pavlović i dr, 2020). Mnoge kompanije dobrovoljno sastavljaju integrisane izveštaje u raznim formatima, ali nekoliko jurisdikcija zahteva ovu vrstu izveštavanja (Deloitte, 2011; Deloitte, Touche, 2011). Međutim, problem kako integrisati finansijsko izveštavanje sa nefinansijskim izveštavanjem još uvek nije rešen. Prisustvo različitih finansijskih okvira za izveštavanje (Međunarodni računovodstveni standar- di - MRS i Međunarodni standardi finansijskog izveštavanja - MSFI, principi), kao i prisustvo nekoliko standarda za nefinansijsko izveštavanje (Global Reporting Initiative - GRI, Price waterhouse Coopers PwC inicijativa za izveštavanje o vrednosti) čini težak proces integracije (GRI - Global Reporting Initiative, 2014; PwC - Price waterhouse Coopers, 2009).

lako integrisano izveštavanje nije obavezno u većini zemalja, sve veći zahtevi stejkholdera za nefinansijskim informacijama doveli su do toga da broj objavljenih integrisanih izveštaja o poslovanju iz godine u godinu raste (Jovanović, Janjić, 2019). Nefinansijske informacije sastoje se od tri glavne kategorije: nematerijalna imovina, ključni pokazatelji učinaka, tj. ključni indikatori uspešnosti ili neuspešnosti (Key Performance Indicators - KPI) i ekološki, socijalni i upravljački parametri (Evropski standardi i smernice - ESG) (Perrini, Vurro, 2010; Labrey, 2015; ICGN - International Corporate Governance Network, 2008).

Potreba za podsticanjem razvoja integrisanih sistema finansijskog izveštavanja se javila usled (Eccles, Krzus, 2010):

1. Koristi od šireg posmatranja učinka (holistički) kroz kombinovanje ekonomskih, finansijskih, socijalnih performansi itd., što omogućava homogenu viziju kompanije i potpun sud o korporativnoj konkurentnosti. 
2. Stvaranja konkurentske prednosti i kako bi kompanije integrisale rezultate upravljanja nematerijalnim resursima u izveštaj o održivom razvoju.

3. Osnaživanje kompanija u kojima je odgovornost ključna dimenzija strategije.

4. Pretežne upotrebe kvalitativnih pokazatelja u poređenju sa kvantitativnim pokazateljima.

5. Priliku da se razume da li društveno odgovorne prakse doprinose razvoju nematerijalnih resursa.

Mnogi autori izražavaju zabrinutost da korporacije mogu da koriste obelodanjivanje informacija o zaštiti životne sredine ne radi veće transparentnosti, već samo radi širenja informacija koje smatraju prikladnim za unapređenje korporativnog imidža (Eccles, Krzus, 2010). Drugim rečima, to znači da kompanije mogu koristiti izveštavanje o društvenoj i životnoj sredini kao odgovor na javni pritisak i pozirati kao „dobri“ korporativni građani čak i kada nemaju snažno socijalno zalaganje za unapređenje životne sredine. Zastupljeno je mišljenje da kompanije koje pozajmljuju sredstva od finansijskih institucija se najčešće odlučuju za dobrovoljno obelodanjivanje informacija o društveno odgovornom poslovanju i uticaju na životnu sredinu. Veće kompanije teže da daju opsežnija obelodanjivanja od manjih kompanija zbog veće prisutnosti u javnosti. Kompanije u industrijama koje više ugrožavaju životnu sredinu (npr. hemikalije, metali, papiri i nafta) obelodanjuju više informacija od kompanija sa manjim negativnim uticajem na životnu sredinu (Stevanović, Petrović Ranđelović, 2012). Dakle, zaštita životna sredine i upravljanje održivim razvojem smatraju se kritičnim faktorima uspeha u kreiranju pozitivnog imidža kompanije u savremenim uslovima poslovanja.

\subsection{Ekološki projekti NIS-a u fokusu održivog razvoja / Ecological projects of NIS in the focus of sustainable development}

Održivi razvoj ne predstavlja samo strateško opredeljenje NIS-a, već i temeljnu praksu. Jedno od osnovnih načela održivog razvoja NIS-a je da svi biznis projekti istovremeno moraju imati pozitivan uticaj kako na zajednicu u kojoj kompanija posluje, tako i na buduće generacije.

NIS grupa je jedan od najvećih vertikalno integrisanih energetskih sistema u Jugoistočnoj Evropi. Osnovne delatnosti se odnose na istraživanje, proizvodnju i preradu nafte i prirodnog gasa, promet širokog asortimana naftnih i gasnih derivata, kao i realizaciju projekata u oblasti petrohemije i energetike. Sedište NIS-a i glavni proizvodni kapaciteti nalaze se u Republici Srbiji: naftna i gasna nalazišta,
Rafinerija nafte Pančevo, skladišta, kao i mreža benzinskih stanica. Osim u Srbiji, NIS delatnost razvija i u regionu Balkana. Regionalna ekspanzija odvija se u dva osnovna pravca - na polju istraživanja i proizvodnje nafte i gasa (u Rumuniji i Bosni i Hercegovini) i kroz razvoj maloprodajne mreže (u Bugarskoj, Bosni i Hercegovini i Rumuniji).

Briga o zdravlju i bezbednosti, kao i posvećenost zaštiti životne sredine predstavljaju prioritete $u$ poslovanju kompanije. NIS realizuje veliki broj projekata usmerenih na zaštitu biodiverziteta i razvoj ekološke svesti pojedinaca i čitave zajednice. NIS objavljuje primarne informacije o zaštiti životne sredine u okviru Izveštaja o održivom razvoju. Godina 2017. je proglašena "Godinom ekologije", jer u toj godini izdvajanja za projekte zaštite životne sredine iznosila su 479 miliona dinara, a ekološki aspekti radnih procesa u kompaniji usklađeni su sa najboljom svetskom praksom. Sva postrojenja NIS-a koja su korišćena za bušenje tokom 2017. godine, su opremljena sistemom „suvelokacije“ (metalnim betonskim bazenima u koje se odlaže otpadni i splačni materijal tokom bušenja). Takođe, u 2017. godini u potpunosti je implementirana praksa pokrivanja lokacija na kojima se izvodi bušenje PVC folijom, kako bi se onemogućio negativan uticaj procesa na životnu sredinu - zemljište i podzemne vode. Rafinerija nafte Pančevo u 2017. godini je postala prvo energetsko postrojenje u Srbiji sa IPPC - integrisanom dozvolom i time je svrstana među najkvalitetnije proizvođače u Evropi i prepoznata kao bitan činilac obezbeđivanja kontrolisanih uslova zaštite životne sredine. Integrisana dozvola je odluka nadležnog organa doneta u formi rešenja kojom se odobrava puštanje u rad postrojenja ili njegovog dela, odnosno obavljanje aktivnosti čiji sastavni deo čini dokumentacija sa utvrđenim uslovima kojima se garantuje da takvo postrojenje ili aktivnost odgovaraju zahtevima predviđenim Zakonom o integrisanom sprečavanju i kontroli zagađivanja životne sredine.

Tokom 2018. godine nastavilo se sa unapređenjem kompetencija zaposlenih i operatera putem obuka, radionica i sastanakasa operaterima i laboratorijama. Održane su 4 radionice na temu upravljanja hemikalijama, kao i radionica na temu upravljanja otpadom i hemikalijama sa predstavnicima Ministarstva zaštite životne sredine, a u saradnji sa Pravnim fakultetom iz Novog Sada obuka „Kaznenopravna zaštita životne sredine". Takođe, tokom 2018. godine nastavljene su aktivnosti na sanaciji istorijskog zagađenja i vraćanju poljoprivrednog zemljišta u prvobitno stanje (NIS, 2018). 
Tabela 2 - Ukupni izdaci NIS-a za zaštitu životne sredine u 2017. godini u milionima dinara

Table 2 - Total expenditures of NIS for environmental protection in 2017 in millions of dinars

\begin{tabular}{|l|c|}
\hline Tretmani odlaganje otpada & 249,783 \\
\hline Tretman emisije u vazduh & 178,980 \\
\hline Ulaganje u kupovinu i održavanje opreme, kao i povezani troškovi stručnog osoblja & 68,203 \\
\hline Osiguranje za odgovornost prema životnoj sredini & 0,01 \\
\hline Troškovi za sanaciju (remedijaciju zemljišta) & 63,738 \\
\hline Ekološko obrazovanje i obuke & 2,030 \\
\hline Eksterne usluge za upravljanje uticajem za životnu sredinu & 242,281 \\
\hline Eksterne usluge sertifikacije menadžment sistema & 2,393 \\
\hline Dodatni troškovi instaliranja zelenih tehnologija & 47,291 \\
\hline Troškovi izrade studija u oblasti životne sredine & 7,762 \\
\hline Troškovi sanacije akcidentnih izlivanja & 3,459 \\
\hline $\begin{array}{l}\text { Naknada za korišćenje voda i naknada za ispuštenu vodu, naknada za korišćenje } \\
\text { vodnog zemljišta }\end{array}$ & 77,195 \\
\hline $\begin{array}{l}\text { Naknada za zaštitu i unapređenje životne sredine - naknada za transport nafte i } \\
\text { naftnih derivata }\end{array}$ & 170,126 \\
\hline Naknada za zaštitu, unapređenje i zagađenje životne sredine & 87,106 \\
\hline
\end{tabular}

Izvor / Source: (NIS, 2017).

NIS je od 2009. godine u realizaciju projekata zaštite životne sredine u svim poslovnim segmentima uložio više od 13 milijardi dinara, od čega je u 2019. godini investirano 534 miliona dinara. Tokom 2019. godine nastavljeno je unapređenje zaštite životne sredine u Rafineriji nafte Pančevo. Pre svega, realizovani su projekti čiji je cilj bio usaglašavanje rada određenog broja postrojenja sa Direktivom 2010/75/EZ o industrijskim emisijama i strožijim graničnim vrednostima emisija zagađujućih materija u vazduh. U cilju eliminisanja negativnog uticaja otpadnih voda na recipijente nastavljeno je sa projektima ugradnje separatora na stanicama za snabdevanje gorivom. $U$ oblasti istraživanja i proizvodnje nafte i gasa primenom savremenih metoda i tehnologija nastavljen je odgovoran odnos prema resursima i zaštititi životne sredine, a nastavljene su i aktivnosti na sanaciji istorijskog zagađenja. Od 2009. godine je sanirano zemljište ukupne površine $150.612 \mathrm{~m}^{2}$. U želji da obezbedi uspešnu budućnost naftnog sektora u Srbiji NIS je u septembru 2019. godine otvorio savremeni Trening centar u Elemiru namenjen zaposlenima u sektoru proizvodnje nafte i gasa. Nastavljeno je sa realizacijom programa kogeneracije kojim se gas koji se ranije spaljivao na baklji sada koristi za proizvodnju električne i toplotne energije čime se, pored ekonomskog efekta, smanjuju i emisije $\mathrm{CO}_{2} \mathrm{u}$ atmosferu (NIS, 2019).

Aktivnosti i rezultati NIS-a u domenu zaštite životne sredine stalno se unapređuju sa ciljem razvoja ekološke svesti pojedinaca i čitave zajednice.

\section{ZAKLJUČAK / CONCLUSION}

Rastući zahtevi za izveštavanjem o uticaju poslovnih aktivnosti kompanije na životno i socijalno okruženje su praćeni činjenicom da mnoge kompanije širom sveta pridaju sve veću pažnju društvenoj odgovornosti i održivosti poslovanja. Korporativna društvena odgovornost (Corporate Social Responsibility CSR) sve više dobija na značaju i u Srbiji, prihvataju ga ne samo velike korporacije, nego i srednja i mala preduzeća i preduzetnici kao svoju konkurentsku prednost. Ulaganje u zaštitu životne sredine je jedan od glavnih prioriteta NIS grupe. NIS brine o zaštiti zivotne sredine kroz različite projekte usmerene na strogo poštovanje najviših ekoloških standarda, efikasno i odgovorno korišćenje raspoloživih resursa, povećanje energetske efikasnosti i upotrebu obnovljivih izvora energije.

Koncept zelene ekonomije je posebno izazovan za siromašne zemlje i zemlje u razvoju, kakva je i naša zemlja. Republika Srbija teži sprovođenju reformskih ciljeva sa naglaskom na Zelenoj agendi. Glavni ciljevi Vlade Srbije u oblasti zaštite životne sredine su uspostavljanje postrojenja za otpadne vode u svim većim gradovima, uz pomoć i podršku međunarodnih institucija i fondova, poboljšanje kvaliteta života ljudi uspostavljanjem sistema za odlaganje čvrstog otpada i borba protiv zagađenja vazduha.

Prema oceni Evropske komisije, Srbija ne pridaje dovoljno pažnje politikama zaštite životne sredine i borbe protiv klimatskih promena. Kada je u pitanju pregovaračko Poglavlje 27 - „Životna sredina i klimat- 
ske promene" koje se bavi zaštitom životne sredine i klimatskim promenama, Evropska komisija ocenjuje da je potrebno da Srbija pre svega ojača administrativne i finansijske kapacitete centralnog i lokalnog nivoa vlasti, da poveća investicije u čistu energiju, kao i da unapredi aktivnosti u cilju povećanja nivoa ekološke svesti. Domicilne kompanije još uvek izveštavaju o održivom razvoju na dobrovoljnoj osnovi. Imajući u vidu brojne prednosti integrisanog izveštavanja, trebalo bi stimulisati takvu praksu izveštavanja među kompanijama.

Održivi razvoj kompanije treba da izbalansira ekonomski razvoj sa odgovornom potrošnjom resursa, boljom zaštitom životne sredine i unapređenjem uslova u društvenoj zajednici. U budućnosti očekuje se dalje približavanje koncepata tradicionalnog finansijskog izveštavanja i izveštavanja o održivom razvoju, čija simbioza treba da unapredi kvalitet eksternog izveštavanja širokog kruga korisnika.

\section{LITERATURA / REFERENCES}

[1] Baldarelli, M.G., Del Baldo, M., \& Nesheva-Kiosseva, N. (2017). Environmental Accounting and Reporting - Theory and Practice. Springer International Publishing AG.

[2] Bebbinghton, J. (2007). Accounting for sustainable development. Oxford: CIMA.

[3] Damnjanović, A., Miličković, M., Jevremović, M. (2020). Troškovi u funkciji upravljanja sistemom zaštite životne sredine, Ecologica, 27(99), 471-478.

[4] Deloitte, \& Touche. (2011). Navigating your way to a truly Integrated Report (pp. 1-67). Available at: http://www.deloitte.com.

[5] Deloitte. (2011). Integrated reporting: A better view? Global sustainability and climate change service. London: Deloitte Global Service.

[6] Eccles, R. G., \& Krzus, M. P. (2010). One report. Integrating reporting for a sustainable strategy. Hoboken: Wiley.

[7] GRI - Global Reporting Initiative. (2014). Pronti per il report? Introduzione al reporting di sostenibilità per le PMI. Amsterdam: GRI. Available at: www.globalreporting.org.

[8] ICGN - International Corporate Governance Network. (2008). Statement and guidance on nonfinancial business reporting.

[9] Jovanović, D., Janjić, V. (2019). Uticaj smernica GRI na izveštavanje o korporativnoj društvenoj odgovornosti, Zbornik: Ekonomski efekti tranzicije i restrukturiranja privrede Srbije, 420-431.

[10] Labrey, J. (2015). Intangibles and integrated reporting: "Reassessing value, rebuilding trust". Paper/discussion presented by Chief Strategy Office, International Integrated Reporting Council
(IIRC) at the WICl Europe, International Policy Conference "Intangibles: The European State of the Art", Paris, Wednesday 6th May 2015.

[11] Mahmoud Ali Mahmoud, O., Ali Mnfid A Abd Ahmed Abuhteara, M., Kovačević, M., Gardašević, J., \& Ali Mohamoud, O. (2020). Značaj inovativnosti i društveno odgovornog poslovanja malih i srednjih preduzeća u uslovima održivog razvoja, Ecologica, 27(99), 486-492.

[12] Mahoney, L. S., Thorne, L., Cecil, L., \& LaGore, W. (2013). A research note on standalone corporate social responsibility reports: Signaling or greenwashing?. Critical Perspective on Accounting, 24(4/5), 350-359.

[13] NIS (2017). Izveštaj o održivom razvoju. Dostupno na: https://www.nis.eu/wp-content/uploads/2020 101/Izvestaj-o-odrzivom-razvoju-2017-sr.pdf.

[14] NIS (2018). Izveštaj o održivom razvoju. Dostupno na: https://www.nis.eu/wp-content/uploads/2020 101/lzvestaj-o-odrzivom-razvoju-2018-sr.pdf.

[15] NIS (2019). Izveštaj o održivom razvoju. Dostupno na: https://www.nis.eu/odgovornost-u-poslovanju/.

[16] Pavlović, M., Erić, I., \& Milanović, M. (2020). The importance of CSR and reporting about nonfinancial information. Ecologica, 27(99), 451-457.

[17] Perrini, F., \& Vurro, C. (2010). Corporate sustainability, intangible assets and competitive advantage. Symphonya: Emerging Issues in Management, 2, 1-8.

[18] PwC - Price waterhouse Coopers. (2009). Corporate reporting framework. Available at: http://www.corporatereporting.com/corpoaratereporting-framework.htm.

[19] Sekerez, V. (2016). Regulatorni okvir i kvalitet izveštavanja o održivom razvoju. Ekonomske ideje i praksa, 20, 53-68.

[20] Stevanović, T., Petrović Ranđelović, M. (2012). Balanced Scorecard održivosti i analiza ekoefikasnosti. Facta universitatis - series: Economics and Organization, 9(2), 257-270.

[21] Thistlethwaite, J. (2011). Counting the environment: The environmental implications of international accounting standards. Global environmental politics, 11(2), 75-97.

[22] United Nations Environment Programme (UNEP), The Global Reporting Initiative (GRI), KPMG \& The Centre for Corporate Governance in Africa. (2013). Carrots and Sticks, Sustainability reporting policies worldwide - today's best practice, tomorrow's trends. Available at:

https://www.carrotsandsticks.net/media/4ldnklxn/c arrots-sticks-2013.pdf.

[23] Zakon o računovodstvu. (2013). Službeni glasnik RS, br. 62/2013. 